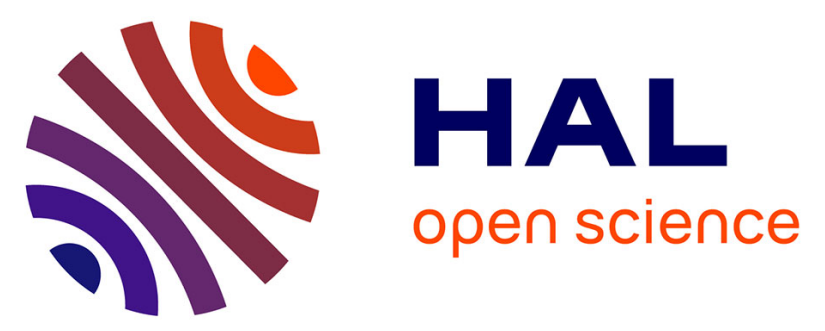

\title{
New insights on fractures deformation from tiltmeter data measured inside the Fontaine de Vaucluse karst system
}

Nolwenn Lesparre, Frédérick Boudin, Cedric Champollion, Jean Chery, C. Danquigny, Han Cheng Seat, Michel Cattoen, Françoise Lizion, Laurent Longuevergne

\section{To cite this version:}

Nolwenn Lesparre, Frédérick Boudin, Cedric Champollion, Jean Chery, C. Danquigny, et al.. New insights on fractures deformation from tiltmeter data measured inside the Fontaine de Vaucluse karst system. Geophysical Journal International, 2017, 208 (3), pp.1389-1402. 10.1093/gji/ggw446 . insu01408482

\section{HAL Id: insu-01408482 \\ https://hal-insu.archives-ouvertes.fr/insu-01408482}

Submitted on 6 Jul 2017

HAL is a multi-disciplinary open access archive for the deposit and dissemination of scientific research documents, whether they are published or not. The documents may come from teaching and research institutions in France or abroad, or from public or private research centers.
L'archive ouverte pluridisciplinaire HAL, est destinée au dépôt et à la diffusion de documents scientifiques de niveau recherche, publiés ou non, émanant des établissements d'enseignement et de recherche français ou étrangers, des laboratoires publics ou privés. 


\title{
New insights on fractures deformation from tiltmeter data measured inside the Fontaine de Vaucluse karst system
}

\author{
Nolwenn Lesparre, ${ }^{1,2}$ Frédérick Boudin, ${ }^{3}$ Cédric Champollion, ${ }^{1}$ Jean Chéry, ${ }^{1}$ \\ Charles Danquigny, ${ }^{4,5}$ Han Cheng Seat, ${ }^{6}$ Michel Cattoen, ${ }^{6}$ Françoise Lizion ${ }^{6}$ \\ and Laurent Longuevergne ${ }^{7}$ \\ ${ }^{1}$ OREME, Géosciences Montpellier, CNRS, Univ. Montpellier, Montpellier, France.E-mail: nolwenn.lesparre@ulg.ac.be \\ ${ }^{2}$ ArGEnCo Department, Applied Geophysics, University of Liège, Liège, Belgium \\ ${ }^{3}$ Laboratoire de Géologie de l'ENS, UMR CNRS 8538, École Normale Supérieure, Paris, France \\ ${ }^{4} U A P V, U M R 1114$ EMMAH, F-84000 Avignon, France \\ ${ }^{5}$ INRA, UMR1114 EMMAH, F-84914 Avignon, France \\ ${ }^{6}$ LAAS-CNRS, Univ. Toulouse, CNRS, INP Toulouse, France \\ ${ }^{7}$ Géosciences Rennes, UMR CNRS 6118, Univ. Rennes 1, Rennes, France
}

Accepted 2016 November 27. Received 2016 November 24; in original form 2016 September 9

\begin{abstract}
SUMMAR Y
Tilt fluctuations can potentially reflect the response of hydrosystems to important rainfall. In this context, long baseline tiltmeters have been installed in an underground tunnel penetrating the Fontaine de Vaucluse karst to study the medium deformation related to solicitations exerted by water infiltrating the hydrosystem. The instruments monitor the tilt as well as its spatial variation. Northward tilts reaching a $1 \mu \mathrm{rad}$ amplitude are observed consecutively to rainfalls. The tilt amplitude is highly correlated with the Fontaine de Vaucluse outlet flow fluctuations. The measured tilt signal is also relatively homogeneous over a $150 \mathrm{~m}$ length. Different types of structure likely to produce such observations are tested in order to identify their location with respect to the tiltmeters, their dimension as well as the amount of water level variation in the structure. Following rainfalls, the infiltration of water modifies the pore pressure, inducing a medium deformation. The hypothesis of a homogeneous surface loading on the Vaucluse plateau is first refuted since the related tilt is much lower than the one measured. The water supplied by rainfalls has to accumulate in discontinuities in order to generate a higher tilt. So, the deformation related to a pressure exerted on a fracture filled by water is assessed. A first study reveals the interest of the tilt homogeneity information that constrains strongly the fracture properties. Thus, the fracture must be located at a distance more than a few hundred metres from the tiltmeters in order to produce a tilt homogeneous in space. If the fracture is initially dry, it must also be filled on a height higher than $150 \mathrm{~m}$ consecutive to a rainfall in order to generate a tilt amplitude in the same magnitude as the one measured. Then, we explore the influence of water level variations on the tilt produced by a fracture located at the interface between the saturated and unsaturated zones, which are thereby permanently flooded. Since several parameters of that model satisfactorily explain the field observations, we discuss how simultaneous geodetical observations could provide complementary information that would further constrain the geometry of the structure at the origin of the medium deformation.
\end{abstract}

Key words: Hydrogeophysics; Fracture and flow.

\section{INTRODUCTION}

Pressure variations in hydrogeological systems induce fluid flow, but also rock deformation. The physical processes at the origin of such deformations are related mainly to pressure changes in the medium and mass transfers. After significant rainfalls, the infiltration of water produces pore pressure changes in the medium (Kümpel et al.
1988). Furthermore, the redistribution of the underground water mass can exert elastic pressure variations by water accumulations (Bawden et al. 2001; Longuevergne et al. 2009; Jacob et al. 2010). Such deformations related to pore pressure change and water redistribution might present different time and spatial scales. Thus, seasonal variations produced by groundwater loading are likely to generate surface motions (Dong et al. 2002). At the scale of a few 
days, important rainy events might also produce local deformations (Braitenberg 1999). When the strain is sufficiently large and occurring over vast areas, surface motion of a few centimetres can be detected by geodetic methods such as GPS or INSAR (e.g. Bawden et al. 2001). In the case of fractured or karstic aquifers, surface motion hardly reaches a few millimetres (Devoti et al. 2015; Schuite et al. 2015) and internal motion detection can only be performed by high resolution tiltmeters, strainmeters or levelling systems. The discovery of the influence of hydrological phenomena on deformations first occurred during the correction of strain and tilt signals intended for investigating crustal deformations associated with tectonics or volcanology (Evans \& Wyatt 1984; Kümpel et al. 1988; Dal Moro \& Zadro 1998; Braitenberg 1999). These studies progressively revealed the interest of monitoring the deformation for understanding the dynamics of complex hydrosystems embedded in heterogeneous media. The role of fractures in water transfer was assessed using tiltmeters by Longuevergne et al. (2009), Jacob et al. (2010), Schuite et al. (2015) and Devoti et al. (2015). The development of accurate borehole tiltmeters further allowed the exploration of near surface water infiltration (Jahr et al. 2009; Hermann et al. 2013) as well as the characterisation of aquifers (Hisz et al. 2013). The capacity of different karstic reservoirs to store water was also studied using tiltmeters placed in underground karstic caves (Gilli et al. 2010; Jacob et al. 2010; Tenze et al. 2012; Devoti et al. 2015).

Karstic hydrosystems are embedded in a medium presenting a complex geological structure with a low permeability matrix through which fractures and drains network allow a faster circulation of fluids (Bakalowicz 2005). The hydrosystem outlet thus presents in a simplified form two interacting types of water transfer: a quick flow response to rainfall through localized structures and a slow matrix drainage contributing to a significant transfer of the total water volume (e.g. Emblanch et al. 2003; Bakalowicz 2005; Garry et al. 2008). So, the understanding of karstic hydrosystem dynamics requires a knowledge of the main hydrologically active structures. Different geophysical methods provide crucial information on the geometry of karstic media and on the temporal evolution of the underground properties (e.g. Jacob et al. 2009; Chalikakis et al. 2011; Carrière et al. 2013, 2016). Tilt measurements are particularly suited to study hydrological systems as tilt deformation of equivalent amplitude can be produced by pressure changes within structures of increasing size at an increasing distance to the measuring point. Therefore the tilt is sensitive to active structures, whether close or far away from the instrument within large systems. Also, the main tilt orientation points towards the pressure source, thus helping to locate the hydrologically active structure. Moreover, tiltmeters allow to achieve measurements with a much higher sensitivity compared to other geodetical tools. Further, tiltmeters are able to record high-dynamical as well as quick pressure changes, contrary to GPS or InSAR systems. Tilt data also demonstrate high stability over time so they can provide information on time scales up to tens of years (Braitenberg et al. 2006).

In this work, we analyse high resolution long baseline tiltmeter signals recorded in the heart of the Fontaine de Vaucluse (FdV) karstic hydrosystem with the aim of determining its strain source. Tiltmeters were installed in the low noise underground laboratory (LSBB, Laboratoire Souterrain à Bas Bruit, www.lsbb.eu). These tunnels on the southern flank of the Vaucluse plateau offer the opportunity to access the unsaturated part of the karst, a few hundred metres above the saturated zone. A long baseline tiltmeter comprising four measurement devices provided accurate tilt signals over more than one year with a resolution of $1 \mathrm{nrad}$ (Boudin et al. 2008). The tilt was thus measured from a long baseline tiltmeter and three smaller aligned baselines that supplied information on the tilt gradient. Because it is infrequent to measure tilts on adjacent baselines, the current experiment offers novel information on the tilt gradient, which will then be exploited as a new and important modelling constrain to localize pressure sources. We also found that the long baseline tilt signal is highly similar to the measured flow at the FdV spring which is the main outlet of the karst hydrosystem.

We first present the context of the experiment. Then, we analyse the correlation between tilt, rain and the outlet flow of the FdV hydrosystem. From those observations, we model and compare the different hydro-mechanical processes able to induce the recorded tilts. Three deformation processes associated with water transfer from rainfall to discharge are considered: (1) a homogeneous load of the plateau above the LSBB due to the weight of surface rain, (2) water pressure in a fracture after rainfalls, and (3) water pressure increase in a previously partially flooded fracture at the interface between the unsaturated and saturated zones. We finally discuss how the most suitable model contributes to improving the knowledge of the FdV karstic hydrosystem.

\section{FIELD EXPERIMENT AND DATA}

\subsection{Geological context}

The LSBB is located in the southeast of France, east of Avignon (Fig. 1). This underground laboratory provides a direct access inside the FdV hydrosystem. The LSBB is excavated in the southern border of the Vaucluse plateau (Fig. 2a) where monoclinic fractured limestone layers dip by $10^{\circ}$ to $20^{\circ}$ to the south (Fig. 3; Jeanne et al. 2012; Sénéchal et al. 2013). The Urgonian Cretaceous reef limestones hosting the aquifer present a thickness of approximately $1500 \mathrm{~m}$ and outcrops throughout the Vaucluse plateau (Masse 1969). The base of the aquifer lies on Valanginian and Upper Hauterivian impermeable marls (Fig. 3). To the south of the plateau, the Apt Basin is covered by impermeable Aptian marls. The FdV hydrosytem is strongly karstified as shown by the presence of dolines and dry valleys that cut through the plateau and result from limestones dissolution (Blavoux et al. 1992). In between valleys seepage through lapies is significant since the soil cover is thin. On flat areas the accumulation of runoff water generates lapies (Blavoux et al. 1992). Dolines present on the plateau appear to be clogged.

The limestone formation is highly fractured with faults and fractures that present extensions from a few metres up to a few kilometres. Two main fault types are observed on the LSBB walls: normal and strike-slip faults oriented at $\mathrm{N} 10^{\circ}-\mathrm{N} 40^{\circ}$ and strike-slip fault oriented at $\mathrm{N} 150^{\circ}-\mathrm{N} 170^{\circ}$, which are also prevailing at the plateau scale. Both types of faults dip steeply between $80^{\circ}$ and $90^{\circ}$ (Gaffet et al. 2003). The LSBB tunnel penetrates the karst medium and the faults network, intersecting some flow paths through the unsaturated zone. Consequently, about forty water flow points have been identified all over the laboratory at different depths from about 30 to about $440 \mathrm{~m}$ (Garry et al. 2008; Barbel-Perineau et al. 2015; Ollivier et al. 2015). Three of them are perennial while the others present much contrasted behaviours, reflecting the complexity of the FdV hydrosystem (Garry et al. 2008; Barbel-Perineau et al. 2015; Ollivier et al. 2015) and the difficulty to globally assess water transfers from surface to the FdV outlet. The analysis of the chemical composition of the water released by a set of fractures favours the multiple paths hypothesis (Emblanch et al. 2003; Garry et al. 2008). The three perennial flows are associated with a slow component, smooth variations of discharge rate, longer 


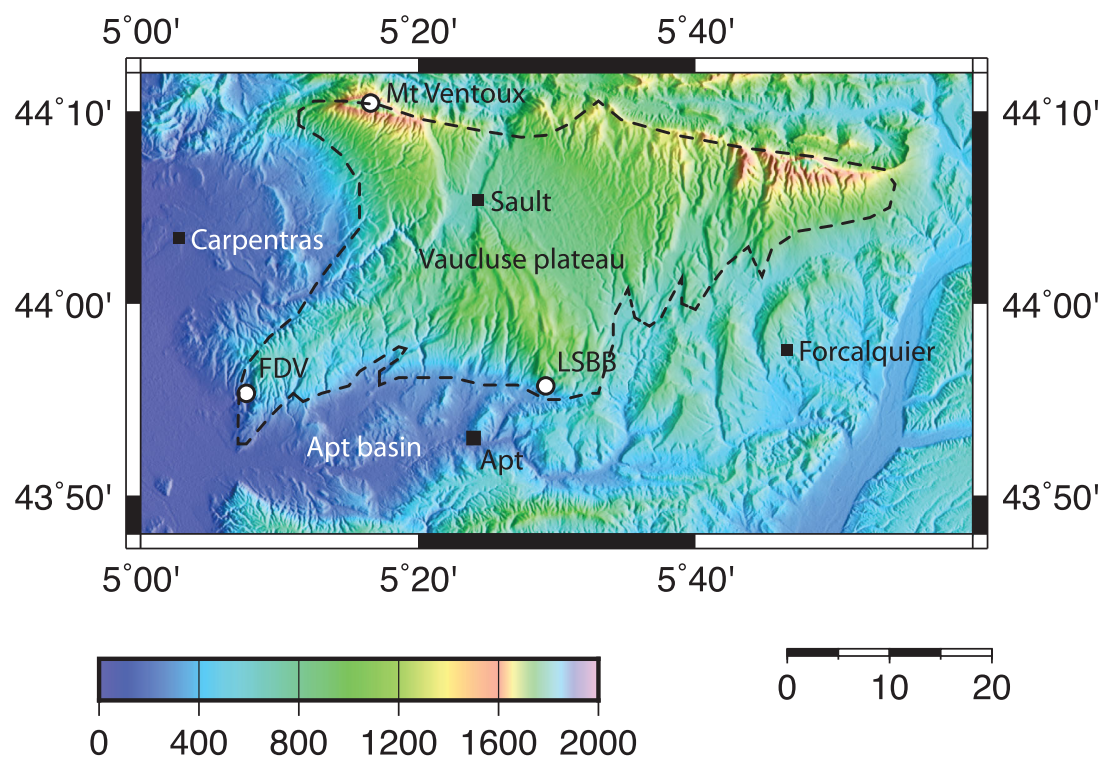

Figure 1. Location of the LSBB and the Fontaine De Vaucluse outlet south of the Vaucluse plateau.

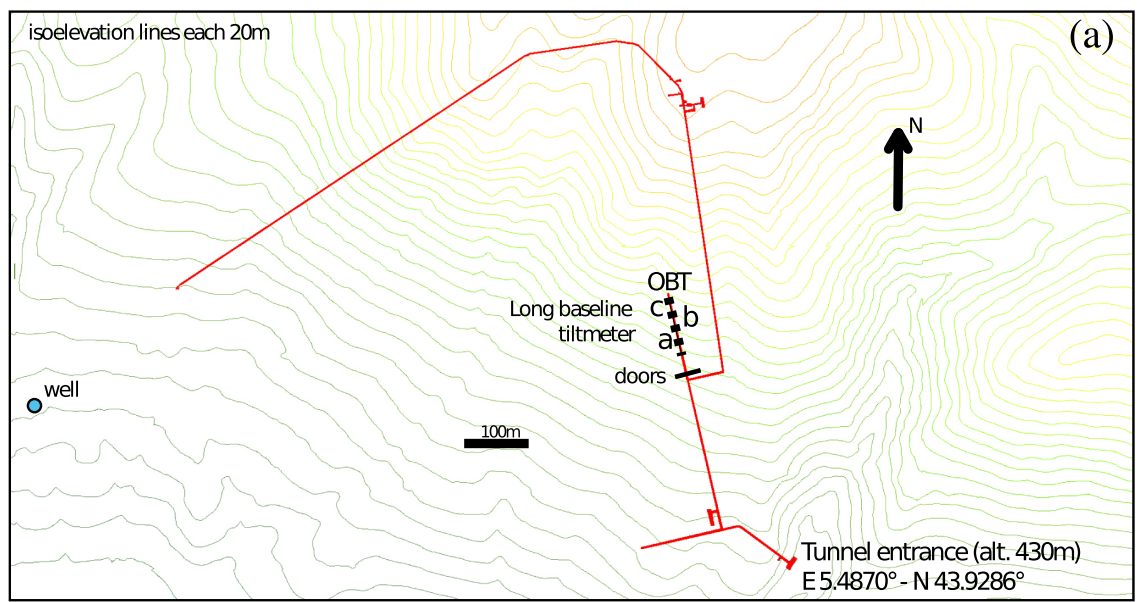

(b)

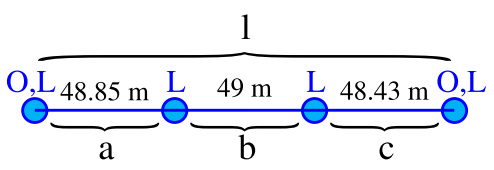

$\longleftarrow$

Tunnel entrance

Legend:

- baselines

baselines vessels

vertical ground borehole

O: optical sensor

L: LVDT sensor

$\mathrm{P}$ : pendulum tiltmeter

a, b, c: small hydrostatic baselines

l: long hydrostatic baseline

Figure 2. (a) Topography above the LSBB, galleries are indicated in red. Vertical deformations were measured at four points in order to provide tilt on a long-base tiltmeter of about $150 \mathrm{~m}$ and on three baselines of about $50 \mathrm{~m}$. Piezometric data were measured from the well located outside, west of the LSBB. (b) Scheme of the tiltmeters location in the tunnel.

residence time and no fast response to precipitations. On the other hand, some flow points are associated with a fast component, they leak water very rarely only in response to peculiar rainy periods. Between these two components, other flow points present intermediate responses to precipitations. They could leak water continuously during several days or weeks with variable residence time and complex, likely hysteretic, behaviours (Emblanch et al. 2003; Garry et al. 2008).

\subsection{Hydrological data}

The FdV outlet is one of the largest karst springs in the world, draining an area of about $1130 \mathrm{~km}^{2}$ (Puig 1987) and supplying the Sorgue river with a considerable average flow of $20 \mathrm{~m}^{3} \mathrm{~s}^{-1}$ (Blavoux et al. 1992; Cognard-Plancq et al. 2006). More than 600 penetrable caves are identified on the plateau, most of which developed vertically with four of them being deeper than $500 \mathrm{~m}$. One of the vertical caves, the Souffleur shaft, reaches the water table at a $750 \mathrm{~m}$ depth (Lefahler \& Sanna 1990; Audra et al. 2004), indicating a low average hydraulic gradient (Blavoux et al. 1992). The FdV spring is located at an altitude of $84 \mathrm{~m}$ and distant of about $30 \mathrm{~km}$ from the LSBB. Exploration in the outlet vertical shaft evidenced the deepness of the hydrosystem that reaches at least $-308 \mathrm{~m}$ from the surface, that is, $224 \mathrm{~m}$ below the present sea level (Bayle and Graillot 1987; Audra et al. 2004). The thickness of the unsaturated zone is then estimated to be around $800 \mathrm{~m}$, while the saturated zone is at least $300 \mathrm{~m}$ thick (Puig 1987; Emblanch et al. 2003). The whole Vaucluse plateau is highly permeable with no surface water (Blavoux et al. 1992) while the water at lower elevation (below $400 \mathrm{~m}$ ) is mostly captured by surface drainage on marl cover (Fig. 3).

Daily pluviometry data from the 24th of April 2012 up to the 9th of July 2013 are recorded at Rustrel (Fig. 4a). Nineteen strong rainfall events inducing precipitations higher than $15 \mathrm{~mm} \mathrm{~d}^{-1}$ have been identified. They are numbered and marked by red vertical lines (Fig. 4a). The average rainfall during this period is $870 \mathrm{~mm} \mathrm{yr}^{-1}$ and the cumulated precipitation per meteoric event is on average $44 \mathrm{~mm}$ for an average duration of $1.5 \mathrm{~d}$. The 


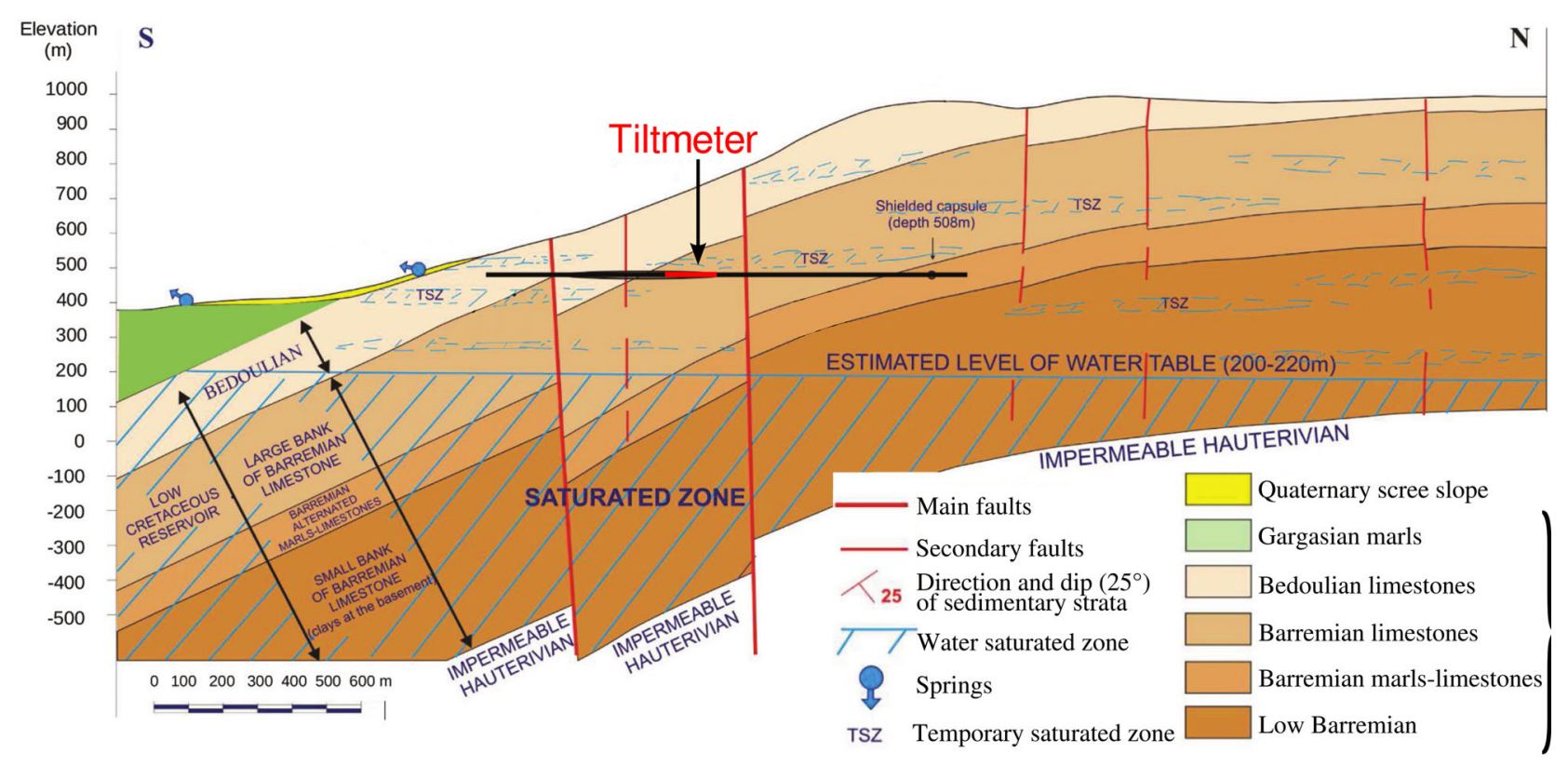

Figure 3. Conceptual south-north cross-section (Sénéchal et al. 2013, modified from Maufroy 2010). The actual vertical shifts of faults are unconstrained. The solid horizontal black line corresponds to the tunnel location.

beginning (end) of rainfalls analysed below are assigned to the first (respectively last) day presenting a daily precipitation higher than $0.5 \mathrm{~mm}$.

Flow observation at the outlet is monitored in the Sorgue river, at the Moulin station, located at a distance of $400 \mathrm{~m}$ from the FdV spring. During the studied period, the average flow is of $20 \mathrm{~m}^{3} \mathrm{~s}^{-1}$, ranging from $4 \mathrm{~m}^{3} \mathrm{~s}^{-1}$ (Fig. $4 \mathrm{~b}$ ) to $50 \mathrm{~m}^{3} \mathrm{~s}^{-1}$ in low and high water situation. The volume of water that can be mobilized is estimated from similar low flow values at $45 \times 10^{6} \mathrm{~m}^{3}$, while the volume of the reservoir storing the water released during high flow rates is evaluated to be approximately $390 \times 10^{6} \mathrm{~m}^{3}$ (Fleury et al. 2007). Flow peaks reach values higher than $50 \mathrm{~m}^{3} \mathrm{~s}^{-1}$ following strong rainy events on the 9 th and the 17 th event (see Fig. 4a) or following successive rainfalls such as the 15 th event. Precipitations occurring after drought periods are not systematically followed by outlet flow increase such as the rainy events 3, 4, 5, 6, 7 and 12 . Likewise, no obvious variation on the flow decay occurred after the 18 th rainy event that followed a strong precipitation event. Flow increase occurs approximately $2 \mathrm{~d}$ after the first day of the corresponding rain, while flow peaks appear $5.4 \mathrm{~d}$ after the first rainy day. At the end of 2014, a well was drilled a few hundred metres southeast to the LSBB to monitor water level variations that fluctuate around an elevation of $165 \mathrm{~m}$. Head variations are highly correlated with the FdV outlet flow $\left(r^{2}=0.93\right)$. A 20 m elevation of the water level is recorded, associated with a flow increase of about $15 \mathrm{~m}^{3} \mathrm{~s}^{-1}$.

\subsection{Tilt data}

Two types of tiltmeters, a hydrostatic and a pendulum type, are installed in the anti-blast tunnel, which is protected by two sets of airlock doors to limit disturbances due to air circulation and temperature variation (Chawah et al. 2015). The hydrostatic, or baseline, tiltmeters are oriented at $350^{\circ} \mathrm{N}$ and are located at $430 \mathrm{~m}$ elevation, that is, a depth of about $250 \mathrm{~m}$ below surface (Fig. 2). Hydrostatic tiltmeters consist of borosilicate vessels connected with horizontal polytetrafluoroethylene tubes in which the liquid level corresponds to a local equipotential of the gravity field (Boudin et al. 2008). Therefore, a medium vertical rotation with respect to the gravity field induces a differential variation of the liquid level in the vessels. The tilt value is then obtained by dividing the difference in liquid level variation by the corresponding baseline length. The tiltmeter is constituted by four vessels equipped with two different sensors measuring the liquid level variations which are subsequently converted into tilt values (Fig. 2b). Two vessels distant by $146.3 \mathrm{~m}$ are equipped with fibre optic interferometers (Seat et al. 2012) and Linear Variable Differential Transformer (LVDT) sensors measuring liquid level variations. The LVDT sensors, detect a linear displacement using a passive electrical sensor by induction. In between, two additional vessels, equipped with LVDT sensors, allow measuring the tilt of three equivalent smaller tiltmeters that present, from south to north, respective baselines of $48.85,49.0$ and $48.43 \mathrm{~m}$ (hereafter denoted as tiltmeter a, b and c; Fig. 2). A pendulum tiltmeter was also installed in a borehole at the end of the tunnel, close to the hydrostatic tiltmeters (Fig. 2b). Over a few months, the pendulum tiltmeter measured the tilt variations as well as their geographical orientation, close to the hydrostatic tiltmeter orientation. The decomposition of the signal on the N$\mathrm{S}$ and $\mathrm{E}-\mathrm{W}$ directions shows that tilt variations following rainfall events mostly occur along the $\mathrm{N}-\mathrm{S}$ axis, but with an amplitude and a phase different from those observed by the hydrostatic tiltmeter (Chawah et al. 2015). In the following, we will consider that hydrologically induced tilt is systematically aligned along the N-S direction, as observed when the deformation source is associated with fractures.

Tiltmeters were set up on April 2nd, nevertheless the first three weeks of data are not considered here as they correspond to the stabilization of the hydrostatic tilmeter. We analyse tilt data from 2012 April 24 to 2013 July 9 beyond which the LVDT signals are perturbed due to defective operation of the sensors. During the experiment, the optical-based sensors are found to exhibit relatively 

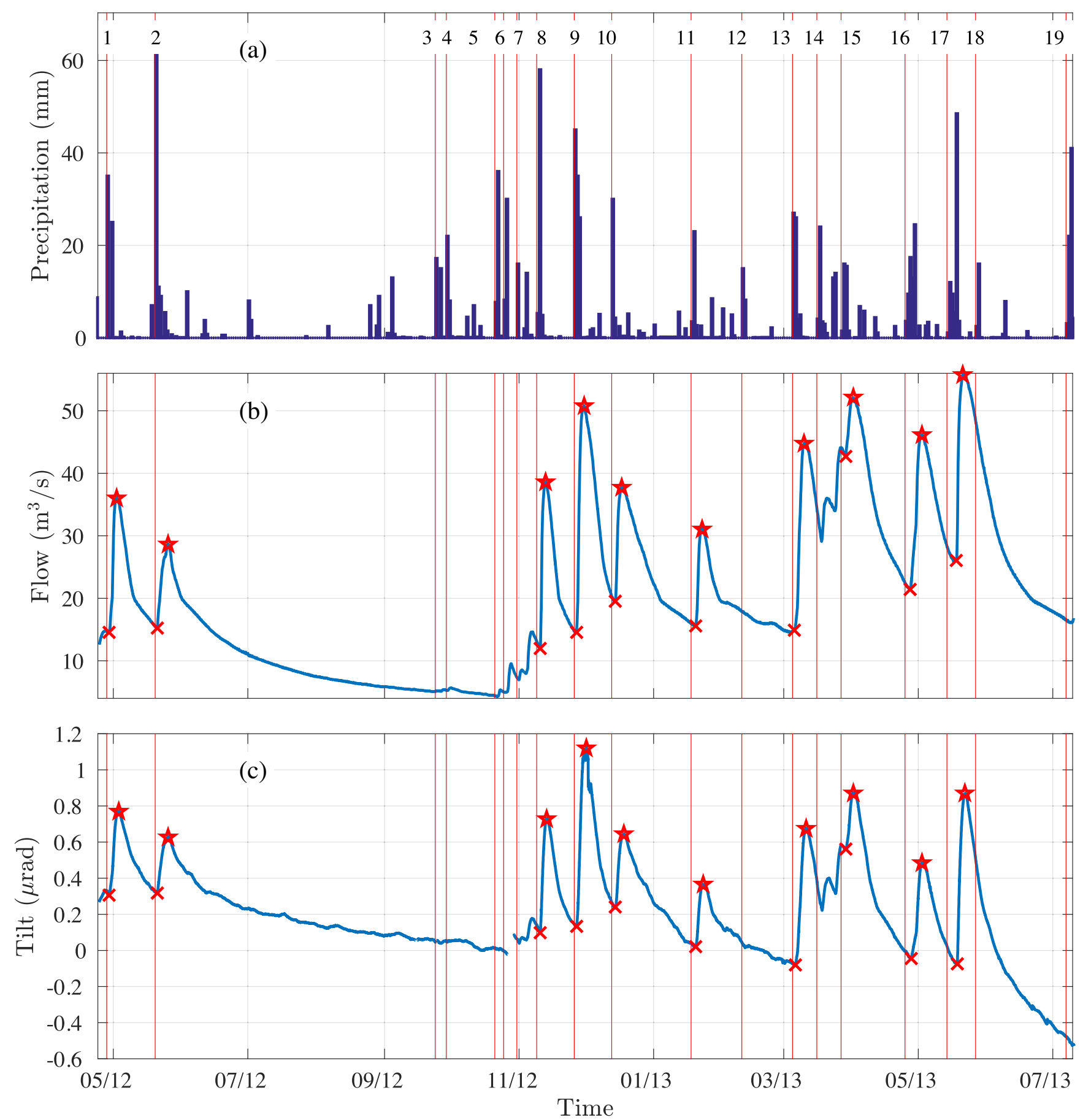

Figure 4. (a) Pluviometry data in $\mathrm{mm} \mathrm{d}^{-1}$. (b) Flow at the FdV outlet. (c) Tilts measured along the $350^{\circ} \mathrm{N}$ direction with the long base of about $150 \mathrm{~m}$. An increase of the tilt indicates that the southern block rises up. Red lines indicate rain events with precipitations higher than $15 \mathrm{~mm}$. Tilt variations higher than $0.3 \mu \mathrm{rad}$ are marked by red stars. The red crosses denote the starting of the flow and tilt increase on the plots (b) and (c), respectively.

weak sensitivity to thunderstorms, while the signature of electrical perturbations is seen on LVDT sensors (jumps). Over a period of $1 \mathrm{yr}$, both the recorded optical and LVDT data along the long baseline show a conspicuous agreement (Fig. 5a). However, the tilt signals on the long baseline display a non-linear drift of about -160 $\mathrm{nrad} \mathrm{yr}^{-1}$ during the experiment. This drift appears to be associated with an anomalous behaviour of the last vessel as it is also observed on the tiltmeter $\mathrm{c}$ and not on the a and $\mathrm{b}$ instruments (Fig. 5b). The source of the drift is currently not fully understood yet, although we suspect a local mechanical origin rather than a measurement deficiency, since both the optical and LVDT sensors display the same tendency. Seasonal variations related to temperature or barometric pressure fluctuations could also affect the signal of the long base tiltmeter, however that influence is difficult to distinguish since the analysed data were collected over a period slightly longer than a year. Nevertheless, the tiltmeter was installed in a tunnel, $250 \mathrm{~m}$ below the surface, closed by two sets of airlock doors limiting disturbances due to air circulation and temperature variation. In 

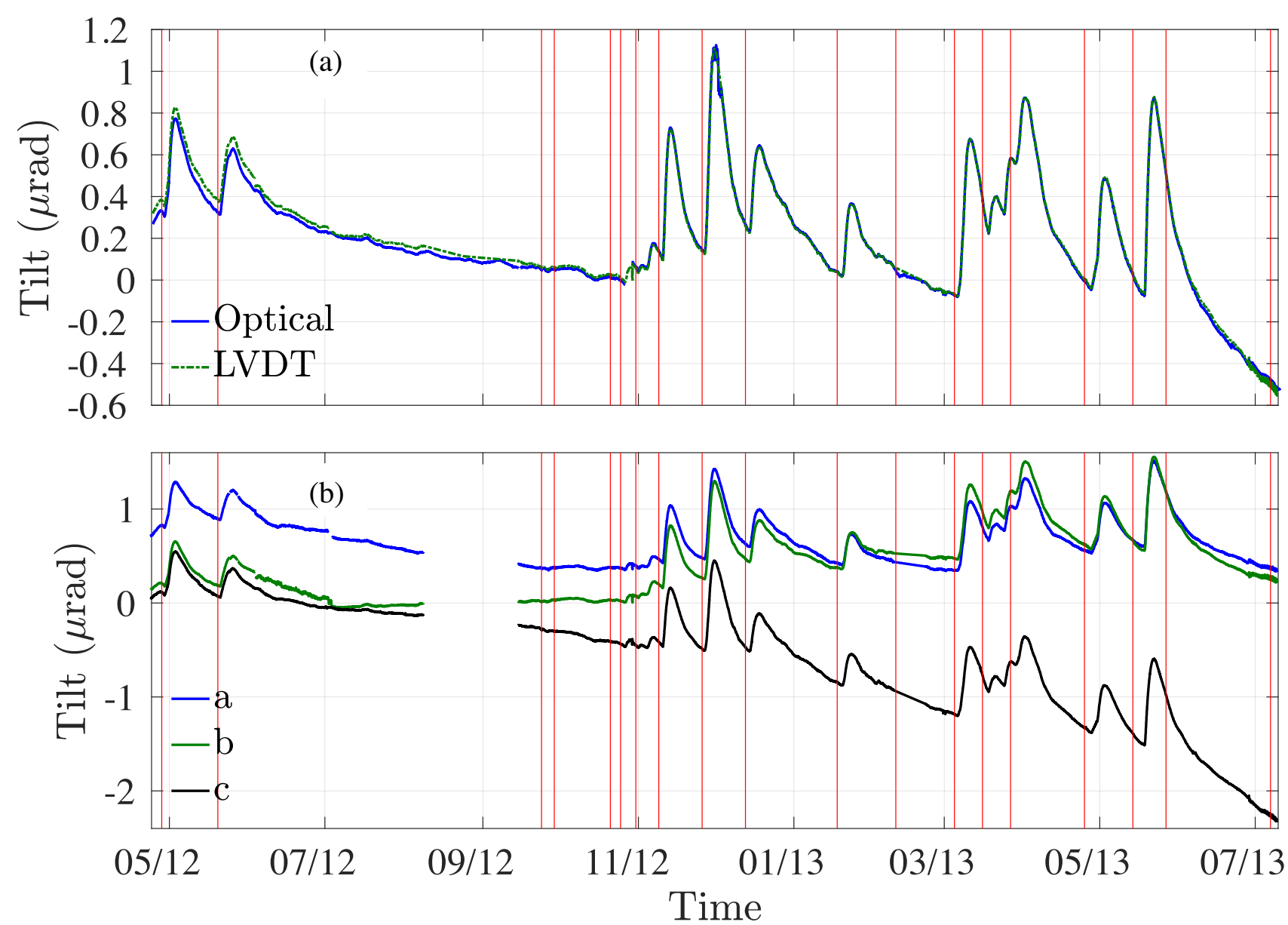

Figure 5. Comparison of the tilts measured with the different sensors. (a) Long-base tilt measured with optical and LVDT sensors. (b) Tilt measured with the smaller instruments a, b and c with LVDT sensors.

the tunnel hosting the tiltmeters, the temperature fluctuates actually with an amplitude lower than $0.05^{\circ} \mathrm{C}$. Maximum perturbations associated with such a thermal variation cannot exceed a few tens of nrad, that is, an order of magnitude lower than the drift (Boudin 2004). In the following, we analyse tilt signals at the temporal scale of a rain event (a few days) and found that the anomalous drift, even though significant over longer periods, does not influence insights inferred from our study.

The tides are not considered here and have been removed from tilt signals using the ETERNA software (Wenzel 1994; Boudin et al. 2008). The subsequent tilt data present peaks occurring after meteoric events (Fig. 4c) which are also followed by flow rise at the FdV outlet, in the Sorgue river (Fig. 4b). For all events, the south direction is rising up after decreasing, in agreement with observations by the pendulum tiltmeter located in a nearby borehole. It has been observed that groundwater fluctuations can affect the tilt signal with a variable orientation (Weise et al. 1999). However, measurements in the FdV hydrosystem show that the tilt in the eastwest direction, extracted from the pendulum data, does not present particular variations after rainfalls (Chawah et al. 2015). Spikes with back and forth variations are not observed following rainfalls as previously reported (e.g. Gilli et al. 2010; Devoti et al. 2015). As the flow measured at the $\mathrm{FdV}$ outlet, the tilt increases on average $2 \mathrm{~d}$ after the beginning of the rainfall, while the peak appears slightly later than the outlet flow one, on average $6 \mathrm{~d}$ after the rain starts (Fig. 5). We select 10 specific events with steep tilt variations over a few days, ranging from 0.3 to $1 \mu \mathrm{rad}$.

\subsection{Deciphering tilt data}

Apart from the dry periods, rainfalls presenting precipitations higher than $15 \mathrm{~mm}$ are followed by outlet flow peaks as well as a strong tilt signal. The flow and tilt (whole time series) are correlated with a coefficient of 0.95 , after removing a long term linear drift on the tilt data. The correlation significance is evaluated using a Student's t-test that rejects the null hypothesis (no correlation) with a 95 per cent confidence level. The amount of flow and tilt increase during rainy events are represented as a function of the cumulated rain during the corresponding rainfalls (Figs 6a and b). Depending on the event, the considered duration of the rain varies between 1 and $3 \mathrm{~d}$. Both tilt and flow variations consecutive to rainy events present a Pearson's coefficient of correlation with the cumulated rain of $R^{2}=0.5$. Nevertheless, both tilt and flow variations are indeed well correlated with $R^{2}=0.88$ (Fig. 6c), suggesting that tilt has a stronger link with flow, rather than rainfall.

The availability of tiltmeters with various baselines allows investigation of the lateral tilt gradient. Selected tilt variations higher than $0.3 \mu \mathrm{rad}$ are detected by all three $\mathrm{a}, \mathrm{b}$ and $\mathrm{c}$ tiltmeters following rain events. Each tilt peak is analysed individually and corrected from a linear drift estimated on data a few hours before the tilt increase until a few days after the tilt decreases. It is shown from the selected events that the peaks amplitudes measured by the three smaller baselines are relatively similar as they differ by less than 10 per cent, except for only one event. We also note that the first two jumps exhibit a discrepancy smaller than 5 per cent in 

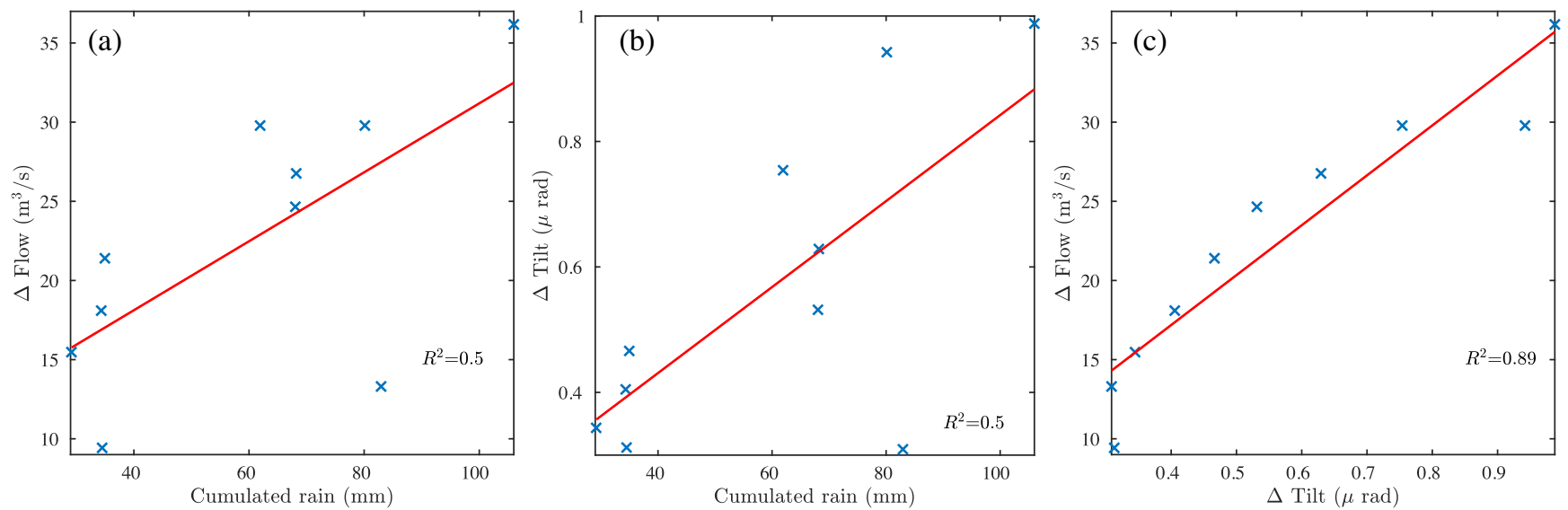

Figure 6. Flow and tilt variations versus cumulated rain of events ( $a$ and b). Flow variations of the Sorgue versus tilt variations after rainy events (c).

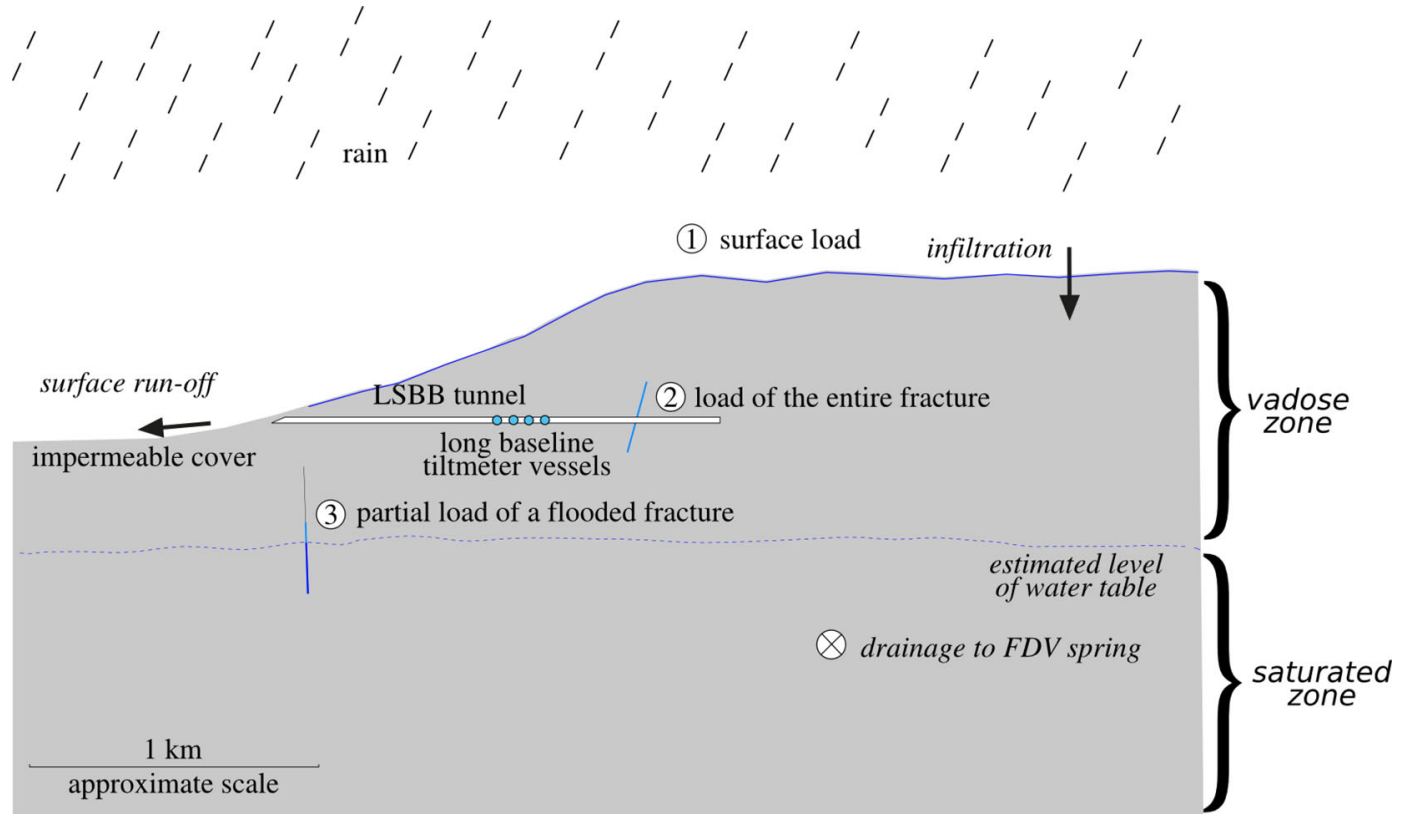

Figure 7. Scheme describing concepts of the different processes tested. The blue segment crossing the tunnel represents the fracture fully saturated as modelled for process 2 . The fracture solicited for the process 3 is composed of an initially flooded part (in blue), a height along which the water level increases (cyan) and a top part (in black). Both fractures of the processes 2 and 3 are assumed to be perpendicular to the tunnel orientation.

amplitude. Thereafter, some electronic components of the LVDT sensor had to be replaced due to storm damage. Nevertheless, the overall tilt measured along the tunnel demonstrates a relatively coherent homogeneity between the three small baselines, suggesting that the deformation source should be located at some large distance from the tiltmeters.

\section{MECHANICAL MODELLING OF MEDIUM DEFORMATION AND TILT}

\subsection{Hydro mechanical processes}

Two processes have been invoked so far to explain hydrologically induced tilt in fractured or karstified aquifers. The first process corresponds to direct water weight (loading) on the topographic surface that can produce internal strain and deformation. This loading effect can be easily modelled using the equivalent surface pressure of the rain column. For example, a typical rain of $20 \mathrm{~mm}$ should exert an equivalent pressure of $200 \mathrm{~Pa}$ on the topography. Water surface loads, as well as atmosphere or snow, are known to produce large effects on a continental scale (e.g. Van Dam \& Wahr 1987) and has sometimes been invoked as a source process for hydrological tilts (Gilli et al. 2010). The tilt can also be influenced by the topography (Gebauer et al. 2009), particularly in the case here where the tiltmeters are located below the flank of an extended plateau presenting a width of up to $20 \mathrm{~km}$ (Fig. 1). The water surface load effect on the FdV hydrosystem deformation is studied in this work under Process 1 (Fig. 7).

A second process results from water pressure changes on fracture walls associated with water infiltration. Pressure changes in fractures can reach large values with a local increase of the water level $(>10 \mathrm{~m})$, as fractures concentrate water drained from large areas and focused on thin structures. Effective stress change is directly related to the water level variation in the fracture and produces both tilt and strain deformation in the fracture vicinity with a rapid decay as the distance from the fracture increases. The deformation induced by water pressure on fractures lips were previously proposed to explain tilt signals in fractured contexts in crystalline or karstic 


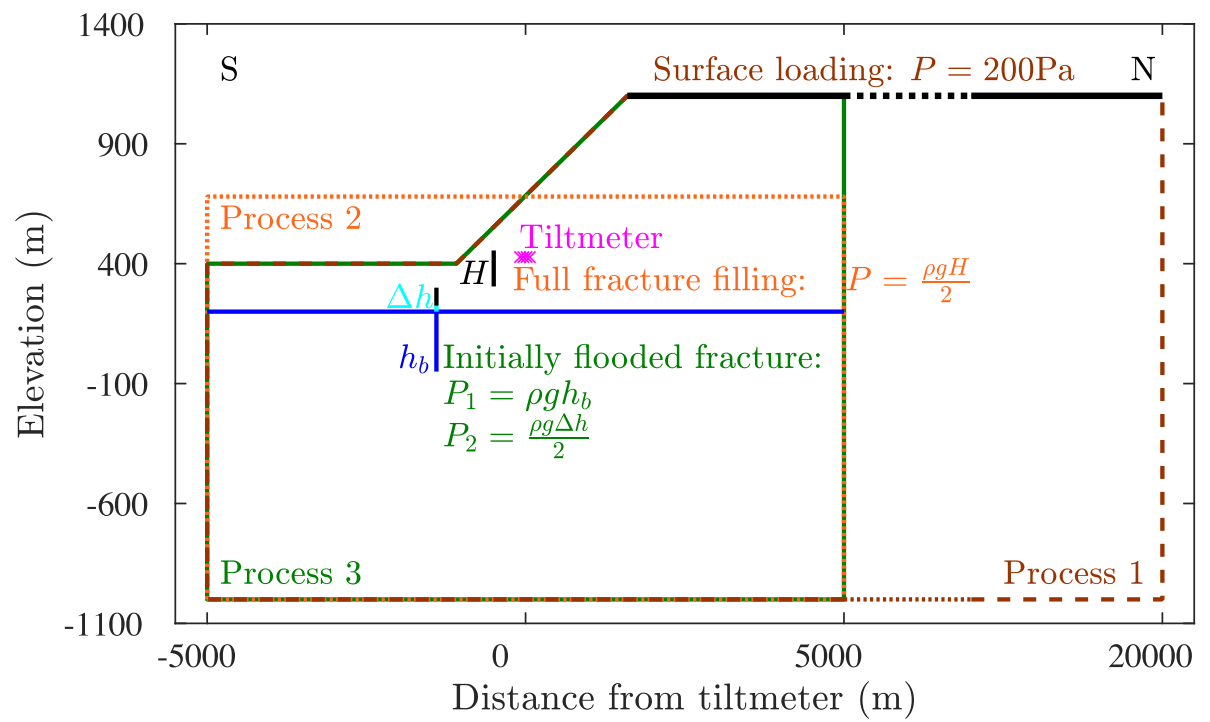

Figure 8. Geometry of the different tested models. From top to bottom, the limits of the models used for the process 1, 2 and 3 are illustrated. The dotted orange lines represent the limit of the entire fracture-filling model with $H$ the fracture's height (Process 2). Green lines correspond to the limit of the flooded fracture model with the blue line showing the water table level (Process 3 ). $h_{\mathrm{b}}$ represents the part of the flooded fracture located in the saturated zone. $\Delta h$ is the water level increase in that flooded fracture. $P_{1}$ is applied over the length $h_{\mathrm{b}}$, while $P_{2}$ is applied over $\Delta h$.

environments (Longuevergne et al. 2009; Jacob et al. 2010; Devoti et al. 2015; Schuite et al. 2015). Here, we consider the loading of a fracture by two distinct mechanisms. First, the impact of water pressure changes following rainfall events in a surface/shallow fracture is tested, corresponding to Process 2, as illustrated in Fig. 7 (Jacob et al. 2010). Then we explore the effect of a water level/pressure variation along a fracture already partially flooded, corresponding to Process 3 in Fig. 7 (Longuevergne et al. 2009).

\subsection{Numerical setup}

The tilt deformation is simulated using the ADELI finite element code (Hassani et al. 1997), based on a simplified 2-D representation of topographic, geological and hydromechanical features of the hydrosystem on an N-S cross-section. The model topography is extracted from a 3 " resolution digital elevation model, that corresponds to a resolution of $20 \mathrm{~m}$ in latitude and $30 \mathrm{~m}$ in longitude. Lateral sides of the model are placed at a distance of $5 \mathrm{~km}$ from tiltmeter locations in order to limit the impact of boundary conditions. The bottom boundary is fixed at an altitude of $-1000 \mathrm{~m}$, that is, more than $1400 \mathrm{~m}$ below the tiltmeters (Fig. 8). The bottom and lateral boundaries of the model are fixed for their normal motion, that is, vertical displacements are allowed for the lateral boundaries, while horizontal displacements are permitted at the bottom boundary. Both surface and internal loads are simulated using pressure boundary condition on free surface edges. The mesh size for the model is around $25 \mathrm{~m}$, allowing representation of fractures with a limited number of 80000 elements. Different values for the mechanical coefficients have been reported in the literature. Mechanical tests performed on rock samples from the LSBB define a Young's modulus of 50.7 MPa and a Poisson coefficient of 0.3 (Gaffet et al. 2003). Petrophysical measurements were also performed on limestones with different porosity sampled in the tunnel where our tiltmeters were located (Jeanne et al. 2012). With the use of empirical relationships the Young's modulus was estimated between 14 and $29 \mathrm{MPa}$ at a centimetre scale and between 40 and $60 \mathrm{MPa}$ at a metre scale (Jeanne et al. 2012). At a few tens of metres scale, elastic parameters were determined experimentally on a sim- ilar karstic medium on the Larzac Plateau (Jacob et al. 2010). Large loads higher than 1 ton were applied on surface, while the deformation was recorded by subsurface tiltmeters. Estimated Young's modulus were as low as $6.4 \mathrm{MPa}$ and the Poisson coefficient was around 0.288 (Jacob et al. 2010). Estimation of the Young's modulus tends indeed to be scale dependant, considering the high heterogeneity associated with fractures and local macroporosity due to the presence of karstic features such as drains. We therefore decided to configure all our models using homogeneous mechanical properties with a Young's modulus of $10 \mathrm{MPa}$ and a Poisson coefficient of 0.28 , since the medium surrounding the LSBB is known to be highly fractured and karstified (Léonide et al. 2012).

\subsection{Numerical simulations}

\subsubsection{Case of surface loading}

For the loading associated with the weight of rainfall, we consider that this load acts at the surface just after the rain event. Indeed, even if rain infiltrates the soil and the epikarst, the total volume is unchanged according to the mass conservation principle. Water can then redistribute laterally, flow downhill and into ground water storage. If the rain does not infiltrate as is the case in impermeable marls to the south, lateral flow to the river partially decreases the loading effect. The load is limited to rain (no runoff and no evapotranspiration are considered) applied on the Vaucluse plateau (Process 1, Fig. 7). No load is applied on the Apt basin since water coming from rainfalls is evacuated by run-off due to the impermeable nature of the underlying geological layer. The northern boundary of the surface loading model is shifted to a distance of $20 \mathrm{~km}$ from the tiltmeter in order to exert a surface pressure on the whole length of the Vaucluse plateau (Fig. 8). On the basis of rain events considered in the previous section, we model the effect of a $20 \mathrm{~mm}$ rain event as a surface load, equivalent to a load of $200 \mathrm{~Pa}$. The resulting tilt produced by such a uniform loading is about $1 \mathrm{nrad}$ which is much smaller than the observed value. In the case where the evapotranspiration would be considered, the amount of effective infiltrated water would be further reduced and hence the estimated 


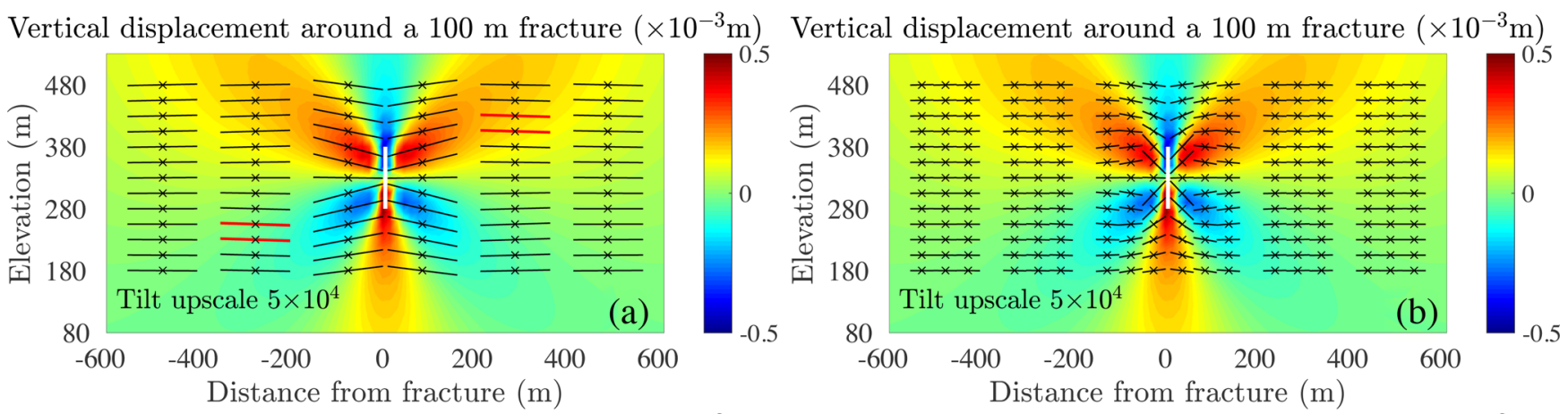

Vertical displacement around a $150 \mathrm{~m}$ fracture $\left(\times 10^{-3} \mathrm{~m}\right)$. Vertical displacement around a $150 \mathrm{~m}$ fracture $\left(\times 10^{-3} \mathrm{~m}\right)$,
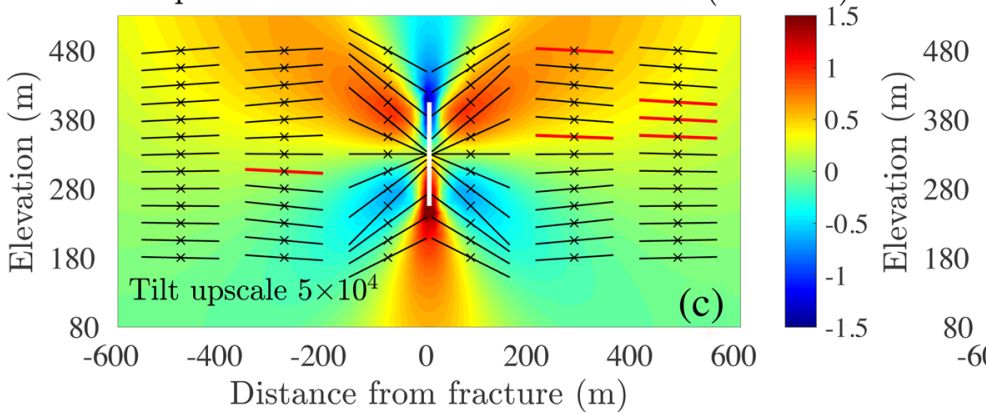

$$
80
$$

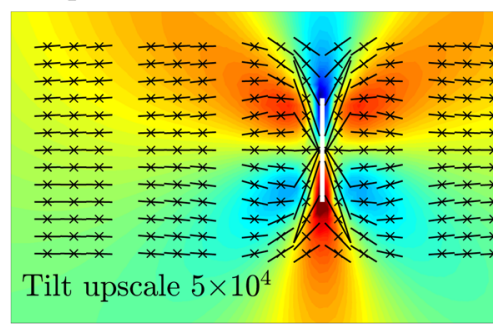

$\begin{array}{cccccc}-600 & -400-200 & 0 & 200 & 400 & 600 \\ \text { Distance from fracture }(\mathrm{m})\end{array}$

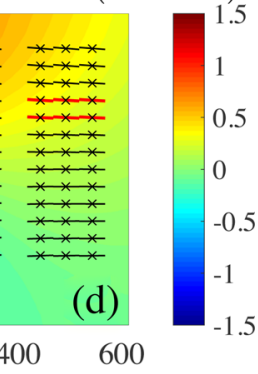

Figure 9. Vertical displacement and induced tilt around a fully loaded fracture, represented by the white vertical line. The initial state corresponds here to an empty fracture. Example with a 100 and a $150 \mathrm{~m}$ height fracture ( $\mathrm{a}, \mathrm{b}$ and c, d respectively). Tilts are illustrated for 150 and $50 \mathrm{~m}$ length baselines (a, c and b, d respectively). Panels (b) and (d) allow then checking the tilt gradient. Red lines highlight tiltmeters location in agreement with measured tilt amplitude variation ( $\mathrm{a}$ and $\mathrm{c}$ ) or a correct tilt amplitude variation and tilt gradient from a small baseline to another ( $\mathrm{b}$ and $\mathrm{d}$ ).

corresponding tilt. Our simulation confirms previous studies that already highlighted that homogeneous surface loading produces tilt jumps much lower than those observed in the field (Gilli et al. 2010; Tenze et al. 2012).

\subsubsection{Case of empty fractures filling with water}

We therefore postulate that the process at the origin of the observed tilt amplitudes might be related to water accumulation in open structural discontinuities present in the medium that naturally focus water flow (Longuevergne et al. 2009; Jacob et al. 2010; Devoti et al. 2015). As the positions and the number of fractures are largely unknown, we use the tilt signal as a guideline to select the class of suitable structures. We assume an east-west orientation of the fracture, perpendicular to the main tilt orientation (Chawah et al. 2015). The following constrains have been employed to select a 'reliable' model:

(1) Tilt variation of the long baseline should be comprised between 0.7 and $1 \mu \mathrm{rad}$,

(2) Tilt variations between the smaller baselines should not exceed 10 per cent of the average value.

Under these constrains, we investigate the position and height of a unique equivalent fracture that can reproduce the observed signals (Process 2, Fig. 7). For a fast estimation of the fracture location and dimension, the topography is not included for that case (Fig. 8).

As empty fractures are filling, the mean water pressure $\mathrm{P}$ applied on the fracture lips that is increasing with water height $H$ equals $P=$ $\rho g H / 2$ with $\rho$ the water density and $g$ the gravity acceleration, which is here applied uniformly on the fracture of height $\mathrm{H}$ (Fig. 8). This pressure corresponds to the average between the pressure applied on the upper $(0 \mathrm{~Pa})$ and lower parts of the fracture $(\rho g H)$. The height of the water column filling fractures in a karstic environment is largely unknown and probably highly variable through such a heterogeneous medium. Differential water heights of $20 \mathrm{~m}$ following rain events have been reported in the well near the western entrance of LSBB (Fig. 2). The FdV hydrosystem is highly heterogeneous and water level variations observed in the well could only reflect the dynamic of a confined aquifer. However, preliminary analyses suggest a correlation between the water movements measured in that well and the flow at the FdV outlet. A physical limit for the fracture water height is the vertical distance between the plateau topography and the phreatic zone that is estimated to be located at about $200 \mathrm{~m}$ above sea level (ASL) as illustrated in Fig. 3. We restrict our numerical search to filling heights between 50 and $300 \mathrm{~m}$, the lower elevation of the centre of each fracture being at $100 \mathrm{~m} \mathrm{ASL}$, slightly under the supposed water level elevation (Figs 3 and 8). Further, depending on the fractures' height, their highest extremity does not exceed an average elevation of $680 \mathrm{~m}$ which corresponds to the surface level above the tiltmeter.

The estimated vertical displacements induced in the medium for each model are converted into tilts. Examples with $100 \mathrm{~m}$ and $150 \mathrm{~m}$ height fractures are shown Fig. 9 with tilts estimated around the modelled fracture for baselines of $150 \mathrm{~m}$ and a set of three aligned baselines of $50 \mathrm{~m}$ long. Consequently, a $100 \mathrm{~m}$ height water loaded fracture may produce a tilt with an amplitude in agreement with the measurements. We note that the instrument has to be located at a distance of about $300 \mathrm{~m}$ from the fracture to measure a signal with the observed amplitude (red lines in Fig. 9a). When adding the tilt homogeneity constrain from a small baseline to another, no instrument located around the fracture matches the requirements in terms of tilt amplitude and tilt homogeneity (Fig. 9b). The fracture therefore has to present a higher height so that an instrument located further away can measure a tilt with the correct amplitude and 

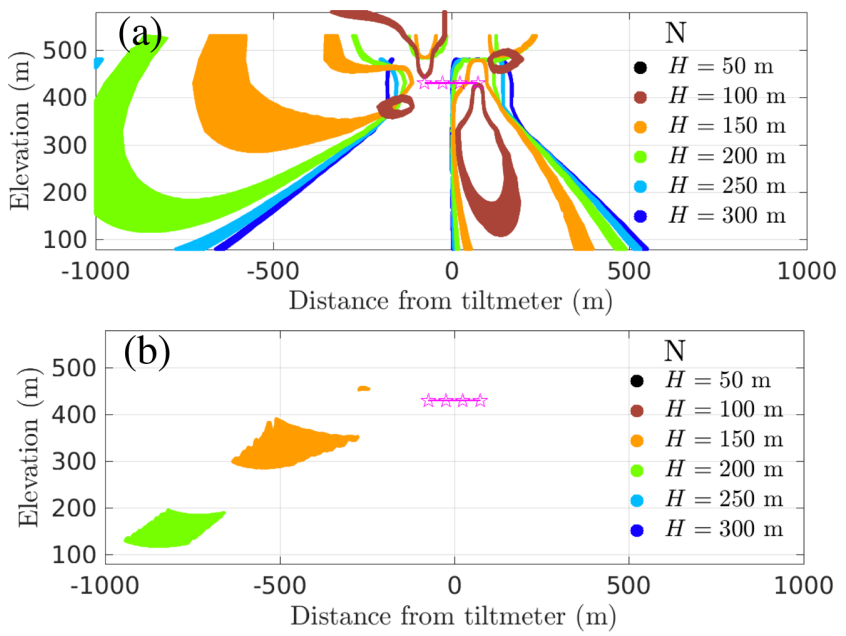

Figure 10. (a) Positions of fractures producing a tilt $\in[0.7,1] \mu \mathrm{rad}$ along a baseline of $150 \mathrm{~m}$. Each coloured point represents the centre of a vertical fracture with different dimensions. (b) Position of fractures producing a tilt $\in[0.7,1] \mu \mathrm{rad}$ along a baseline of $150 \mathrm{~m}$ as well as a tilt gradient lower than 10 per cent between the three $50 \mathrm{~m}$ baselines. Pink stars denote the long baseline vessels.

a homogeneous gradient, as illustrated with a $150 \mathrm{~m}$ high fracture (red lines in Fig. 9d). From the analysis of the models representing fractures of different sizes, the height of the fracture and its location with respect to the instrument can be roughly estimated. The location of fractures presenting a northward tilt on the longbase instrument and an amplitude between 0.7 and $1 \mu$ rad are represented in Fig. 10(a). Each coloured point represents the middle of a selected fracture, the colour corresponding to different water height. Smaller fractures have to be located close to the long-base tiltmeter, typically less than $200 \mathrm{~m}$ from the closest vessel for a $100 \mathrm{~m}$ high fracture (Fig. 10a) for producing the observed tilt signal amplitudes, whereas larger fractures could be located at distances of up to $700 \mathrm{~m}$. If we select fractures producing a tilt gradient below 10 per cent from one small baseline to another, we see that the fractures domain is greatly reduced (Fig. 10b). The smaller likely fractures require water pressure height change of $150 \mathrm{~m}$ and are located at a distance between 250 and $550 \mathrm{~m}$ from the first vessel. Likely fractures are also mainly concentrated south of the tiltmeters in order to produce a homogeneous north tilt. The 2-D

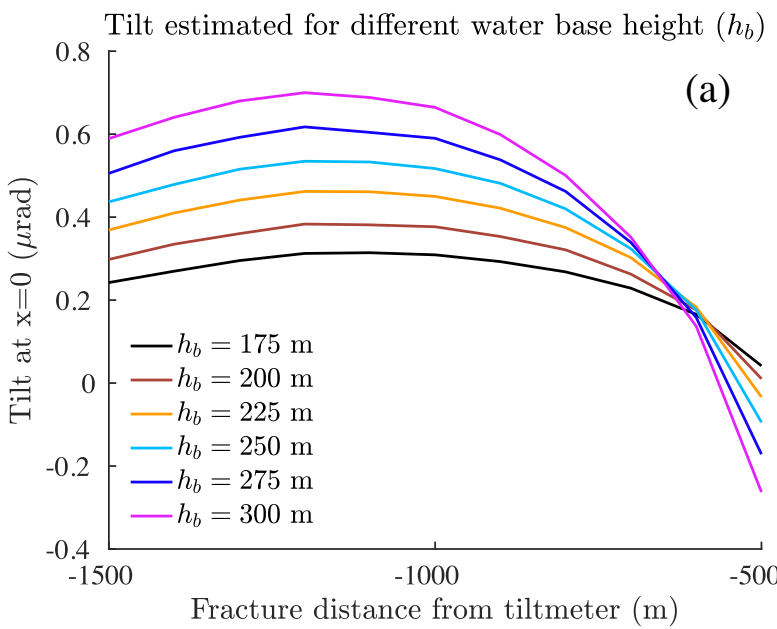

models tested here are homogeneous due to the lack of information on the medium mechanical properties. Results provide then a rough estimate of the hydrologically active structure characteristics. However, this study involving a unique fracture geometry highlights the value of gradient tilt measurements for restraining the search for structures capable of producing the observed signals.

\subsubsection{Case of partial loading on a flooded fracture}

Tilts induced by water level increase in a partially flooded fracture allows applying smaller water height changes for a similar deformation (Longuevergne et al. 2009) (Process 3, Figs 7 and 8). Due to the location of the LSBB facility under the rim of the Vaucluse plateau, the impact of the topography on deformation should be investigated (Figs 7 and 8). Indeed, it has been shown that topographic gradients may be a potential cause of heterogeneous strain and tilt (Meertens \& Wahr 1986). In the case studied here, the Apt basin to the south stands at $400 \mathrm{~m}$ elevation while the plateau to the north is at $1100 \mathrm{~m}$. Consider then a $350 \mathrm{~m}$ height fracture submerged in the first $250 \mathrm{~m}$ height, and a $25 \mathrm{~m}$ water level increase (Fig. 8c). The pressure increase $P_{1}=\rho \times g \times \Delta h$ is applied on the $250 \mathrm{~m}$ flooded section of the fracture (blue section Fig. 8c). A second pressure $P_{2}=\rho \times g \times \Delta h / 2$ is applied on the section of the fracture which was initially dry between 250 and $275 \mathrm{~m}$ (cyan section Fig. 8c). This process allows smaller water level increase considering that pressure change is applied on the entire flooded fracture depth. The assumption requires partially flooded fractures located at the limit between the unsaturated zone and the water table. Hence, the relative vertical position of the fractures to be investigated is constrained by the groundwater level at an altitude of $200 \mathrm{~m}$ (Figs 3, 7 and 8). By comparison, tiltmeters are located below the dip of the southern plateau flank at an altitude of $430 \mathrm{~m}$.

We first test the influence of the flooded fracture height, or water base height $h_{\mathrm{b}}$ on the tilt signal. $h_{\mathrm{b}}$ varies between 175 and $300 \mathrm{~m}$ while the fracture presents a $350 \mathrm{~m}$ height and the increment of the water level $\Delta h$ is fixed to $25 \mathrm{~m}$. We also explore the influence of the distance of the fracture to the tiltmeter, with $\mathrm{X}=0$ corresponding to the middle of the long-base tilmeter location. Tilts estimated from the different models show that several fracture locations or dimensions could match the measured tilt amplitude, with a low tilt gradient (Fig. 11a). In particular fractures located at positions $\mathrm{X}$ between -1500 and $-800 \mathrm{~m}$ with flooded height greater than

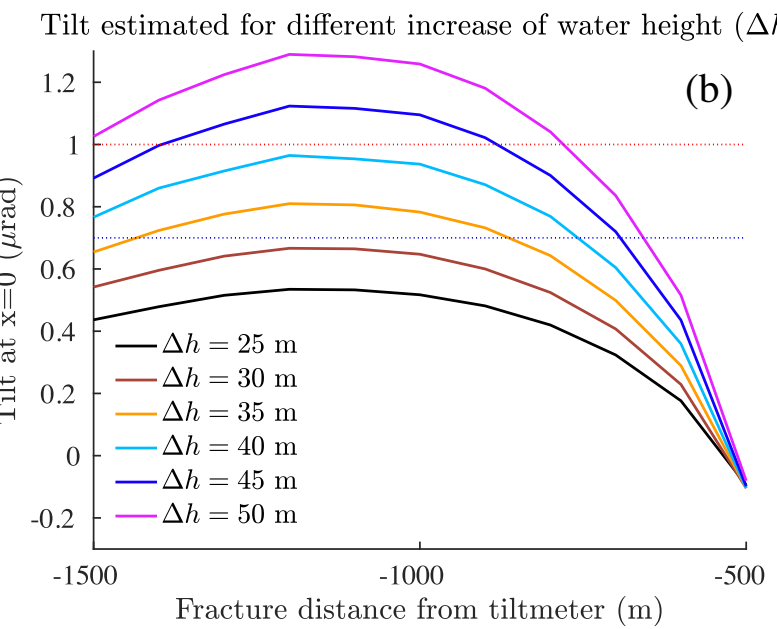

Figure 11. (a) Tilt estimated for different water base heights $\left(h_{\mathrm{b}}\right)$ following a water level increase of $\Delta h=25 \mathrm{~m}$ in a $350 \mathrm{~m}$ fracture. (b) Tilt estimated for different water level increase $\Delta h$ for a $350 \mathrm{~m}$ fracture and a water base level of $h_{\mathrm{b}}=250 \mathrm{~m}$. 
$h_{\mathrm{b}}=250 \mathrm{~m}$ are found to generate suitable tilt values. We also examine the impact of the fracture height on the tilt with fixed $h_{\mathrm{b}}$ and $\Delta h$ values. For a fracture height varying between 300 and $400 \mathrm{~m}$ we observe no significant tilt variations that remain lower than 10 per cent (difference lower than 15 nrad, not shown). We then develop models with a $350 \mathrm{~m}$ fracture, initially flooded with a height $h_{\mathrm{b}}=250 \mathrm{~m}$ and apply different water level increases of $\Delta \mathrm{h}$ between 25 and $50 \mathrm{~m}$ to observe the tilt response at the instrument location (Fig. 11b). For $\Delta h$ between 35 and $40 \mathrm{~m}$, and fractures located between $1400 \mathrm{~m}$ and $900 \mathrm{~m}$ from the tiltmeter, the estimated tilt corresponds to values between 0.7 and $1 \mu \mathrm{rad}$. Since the fractures tested are relatively distant from the instrument, the studied models also generate a variation of the estimated tilt smaller than 6 per cent from a small baseline to another. Thus, additional information are required to constrain the fracture location and the water level variation at the origin of a given tilt change. Unfortunately, no well data were measured during the tilt time range that could be used to deduce a relationship relying tilt and head level variations in order to optimise the selection of the equivalent fracture producing the observed medium deformation.

\section{DISCUSSION}

Tilt fluctuations measured inside the FdV's unsaturated zone demonstrate a high correlation with hydrological events. The southern section of the instrument rises up after rainfalls, in average $2 \mathrm{~d}$ after the rainfalls start, similarly to flow increase at the outlet. Subsequently, a few hours after the flow starts decreasing, the tilt signal also decreases towards its initial value. Out of dry period, the measured tilt variations following meteoric events present a linear relationship with flow increases at the FdV outlet. The tilt amplitude measured at the LSBB attains a value of $1 \mu \mathrm{rad}$. Moreover, the innovative observation of the tilt homogeneity from a small baseline to another proffered crucial information that constrained strongly the choice of the deformation model.

We first studied and subsequently eliminated the hypothesis of a superficial uniform load following a rainfall that produces a tilt signal much smaller than the observed one. We then tested the assumption of an initially dry fracture that fully saturates with water as invoked in a previous hydrogeodesical study (Jacob et al. 2010). Such process requires large structures remotely located from the tiltmeter, invoking water height greater than $150 \mathrm{~m}$ consecutive to a heavy rainfall. Vertical shafts emerging on the plateau effectively present fast water level variations on the order of a few hundred metres consecutive to important rainfall (Naomi Mazzilli personal communication). Nevertheless such observations show that the water level in those shafts decrease much faster than the measured tilt signal. The actual variations of the water level in thin fractures are unknown and complementary data that constrain the medium deformation and the water table fluctuations are required to restrict the characteristics of the hydrologically active structure. We also observed that the insertion of the topography affects the tilt estimates (not shown) however the influence of the topography on the tilt is much lower than the impact of pressure changes related to the water level increase in a fracture. So, we modelled a flat surface here in order to reduce the number of simulations by assuming a symmetry of the deformation along the fracture axis as observed on Fig. 9. We also tested the deformation produced by tens of empty fractures smaller than $150 \mathrm{~m}$. We observed that the fractures have to be close enough to interfere constructively in the generated deformation, but that the vertical deformation induced by a set fracture is not additive when the fractures are nearby. The set of fracture has also to be located relatively far from the tiltmeter to produce a homogeneous lateral gradient. As a result the deformation produced by the set of fractures required an increase of the water level higher than $100 \mathrm{~m}$ to reproduce the tilt signal observed. Furthermore, that model concept presents a high number of configurations to explore such as the distance between fractures, the number of fractures in addition to their location and height. So we preferred to explore another concept of model with fractures located deeper and so closer to the water table level.

We thereby employed a more conclusive model where the water level is slightly increased in a fracture initially partially flooded, as performed by Longuevergne et al. (2009). The induced deformation of the medium allows working with fractures located deeper, at the level of the water table average elevation. Such a concept clearly illustrates that a fracture partially flooded on a $250 \mathrm{~m}$ height requires a $35 \mathrm{~m}$ water level increase to produce a rise of the southern side of the tilt sensor with an amplitude and a tilt gradient in agreement with the observations. The initial water height in the fracture corresponds to a possible water table elevation. The location of the fracture at the interface of the saturated and unsaturated zones is supported by estimates of water level variations based on observations that are not concomitant with tilt measurements. Several of the tested models could indeed be selected depending on the position of the fracture along the S-N axis. Different values of the water level increase, between $25 \mathrm{~m}$ and $50 \mathrm{~m}$, were also investigated and showed that a fracture located at a distance slightly greater than $1 \mathrm{~km}$ south of the tiltmeter induces deformations in agreement with the observations. This 'deep' fracture system is moreover technically justifiable to explain the excellent correlation between the tilt observations and the discharge data measured $30 \mathrm{~km}$ away from the instruments.

The medium deformation induced by the dynamics of hydrosystems previously observed in karstic systems was assumed to be associated with the water filling of shallow fractures (Gilli et al. 2010; Jacob et al. 2010; Devoti et al. 2015). Jacob et al. (2010) and Devoti et al. (2015) tested the influence of superficial fractures filling by water after rainy events. In both studies, the structures are assumed to be located in the epikarst that plays a role in shallow water storage. Gilli et al. (2010) observed sign changes in tilt signals and thus invoked the presence of water storage in epikarstic fractures as well as the filling of deeper reservoirs that could influence long term tilt variations. Devoti et al. (2015) also noted tilt sign change variations but with a very fast response and hence forwarded the complexity of the epikarstic structure to explain the tilt signals' sudden and contradictory variations. In the FdV's hydrosystem, zones of water storage were inferred in the unsaturated zone, somewhere above the LSBB tunnel (Emblanch et al. 2003; Garry et al. 2008). However water flows from these reservoirs mostly present a very slow response to meteoric events (Garry et al. 2008; Ollivier et al. 2015; Carrière et al. 2016) and are thus unable to be used to explain the tilt variations otherwise better correlated to the FdV flow.

From the 2-D homogeneous models tested in this work, we deduced tilt variations with similar orders of magnitude and lateral variations as those observed from the investigation of the likely fracture geometry and location. These models could then be applied to other karstic systems presenting deep perennial aquifers, a high degree of fracturation and a well-developed karstic network. By designing a more elaborate model it would be possible to simulate the influence of water transfers in the medium on its deformation. The full shape of the tilt response could then be more accurately analysed in order to improve the knowledge on water circulations and storage in the $\mathrm{FdV}$ hydrosystem in addition to 

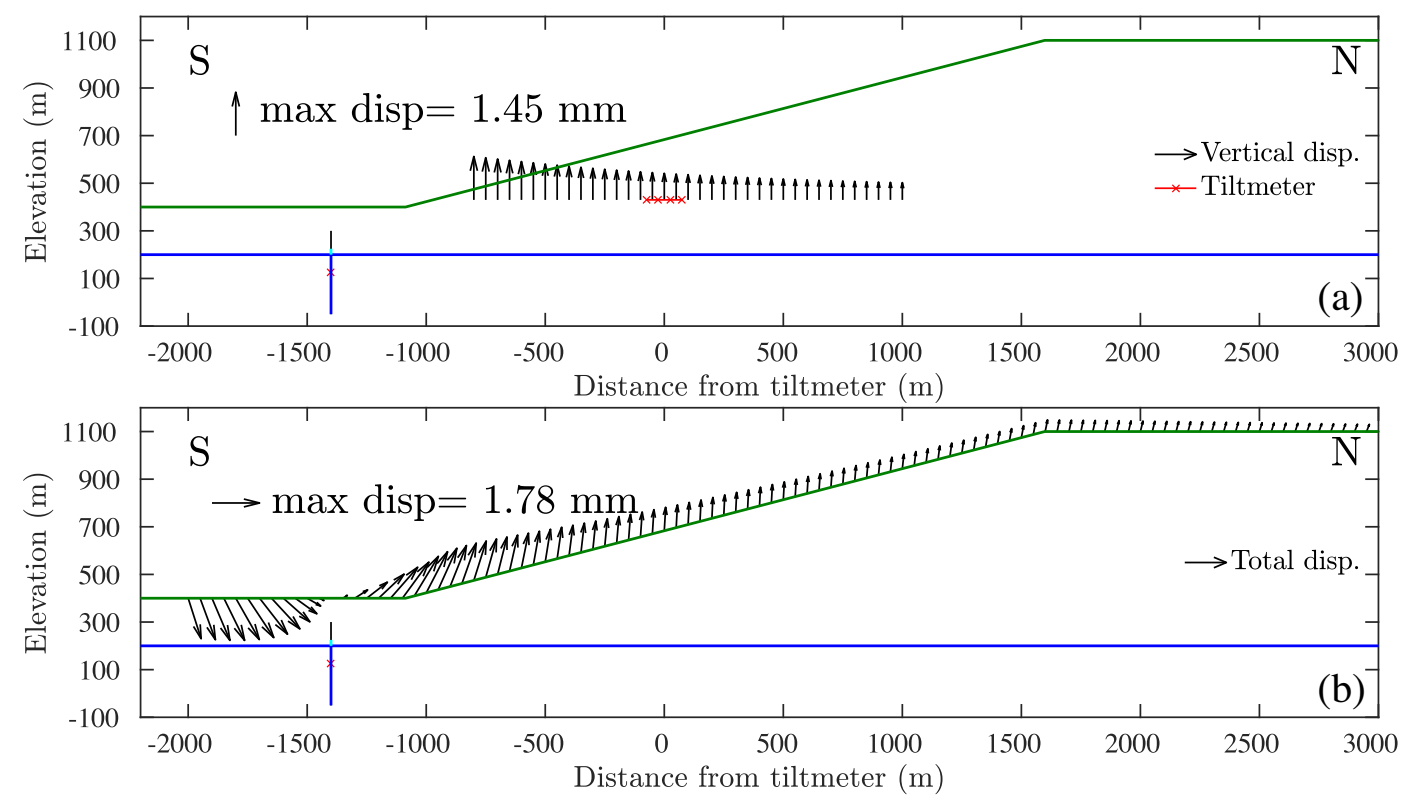

\section{— Fracture location — Ground —-Initial water level}

Figure 12. Displacements produced by a fracture of $350 \mathrm{~m}$ height, located at $1400 \mathrm{~m}$ south to the tiltmeter. The water base level of $250 \mathrm{~m}$ is increased by $25 \mathrm{~m}$. Arrows indicate the vertical displacement along the tunnel (a) and the total displacement (vertical plus horizontal components) at surface (b).

offering a better understanding of the dynamics of fractures located in between the unsaturated and saturated zones. Complementary tilt measurements along the LSBB galleries as well as underground and surface levelling monitoring would further help to refine the geometry of the source of deformation produced by the dynamics of the hydrosystem. The models we developed could then be applied to estimate the tilt along the LSBB tunnel. For instance, if we select the fracture located at a position $X=-1400 \mathrm{~m}$ from the tiltmeter centre, the vertical displacement induced by such a fracture due to a $25 \mathrm{~m}$ water level increase is presented in Fig. 12(a). Deploying several tiltmeters at different locations along the tunnel could also help to constrain the fracture location and dimensions inducing the medium deformation. Surface displacements (vertical and horizontal) can also be computed from such models and compared to GPS data and InSAR/levelling observations following rainy events (Fig. 12b). The time lag between INSAR acquisitions should be lower than a few weeks. Despite the limited precision of GPS data, a preliminary analysis of a data set located on the bottom of the southern plateau rim suggests northward displacement following rainy events in agreement with the model we selected. Complementary information on the deformation would enable further refinement of the location of the structure solicited by water level changes. The estimation of the ratio between horizontal and vertical displacements also provides an insight into the ratio between the source depth and its lateral extension (Devoti et al. 2015). In addition, continuous gravimetric measurements performed with supraconducting gravimeters simultaneously at the surface and in the tunnel would provide complementary information on the water transfer and on the stored volume in the unsaturated zone (Jacob et al. 2009). Furthermore, a better accuracy on estimating the Young's modulus around the tunnel could be obtained from an imagery of shear and compressional wave velocities. Their comparison would subsequently lead to improve the modelling of the medium's mechanical properties in order to better refine tilt estimations since displacements are linearly related to such parameters.
Furthermore the model could take into account the spatial variations of the medium mechanical properties, that is, the medium heterogeneity, thus improving the deformation estimates.

\section{CONCLUSION AND PERSPECTIVES}

Measurements of tilt variations in the inner part of the FdV's unsaturated zone illustrated a conspicuous correlation with hydrological observations highlighting the role of water circulations on the medium deformation. From the measured tilt and tilt gradient data we have investigated the dimension and the location of a partially flooded fracture in which a water level increase is likely to produce the tilt amplitude and homogeneity observed. The corroboration of experimental measurements and modelling estimations suggested that the fracture that induces the observed deformations is located in between the saturated and unsaturated zones, about $1 \mathrm{~km}$ south of the long baseline tiltmeter. A few tens of metres of the water level increase after precipitations have been sufficient to produce the observed deformations when the fracture is initially flooded to $250 \mathrm{~m}$. Estimated deformations using the proposed models inherently imply that complementary geodesic and hydrologic data would be required to further refine the equivalent fracture characteristics and to explore the features of a set of fractures potentially related to the medium deformations.

The pertinence of the tilt gradient monitoring, using baselines of $50 \mathrm{~m}$, has also been demonstrated by this experiment since the recorded data pointed to the necessity to consider a fracture located at the water table elevation for explaining the observed tilt amplitude and lateral homogeneity. By comparison, previous studies of tilt variations measured in karstic environments favoured the presence of fractures close to surface, in the epikarstic zone (Jacob et al. 2009; Devoti et al. 2015). Tilt gradient measurements could then complement conventional tilt experiments performed using long baselines by adding liquid level measurements along the deployed baseline. The use of the tilt gradient information could also help 
filter the local strains variations produced by fractures located close to the tiltmeters (d'Oreye 2003; Boudin 2004). Concerning applications, such a set-up could be applied for monitoring, for instance, the deformation of the medium surrounding geological storage sites dedicated to $\mathrm{CO}_{2}$ or other types of gas (Vasco et al. 2010; Rutqvist 2012).

\section{ACKNOWLEDGEMENTS}

The authors acknowledge Météo-France for supplying the data, the HyMeX database teams (ESPRI/IPSL and SEDOO/Observatoire Midi-Pyrénées) for their help in accessing the data. Flow data were produced by the SPC Grand Delta and supplied by the Banque Hydro - MEEDDAT/DGPR/SRNH. The experiments benefited from ANR support through the LINES project (ANR-08-RISKNAT-01202/LINES). The work of N. Lesparre was supported by the $\mathrm{H}^{+}$ network and the French Institut National des Sciences de l'Univers of the Centre National de la Recherche Scientifique. The authors would also like to thank the technical staff of LSBB-Rustrel for their assistance and advice during the installation and the maintenance of the tiltmeters. Comments made by two anonymous referees helped us to improve the manuscript.

\section{REFERENCES}

Audra, P., Mocochain, L., Camus, H., Gilli, É., Clauzon, G. \& Bigot, J.Y., 2004. The effect of the Messinian Deep Stage on karst development around the Mediterranean Sea. Examples from Southern France, Geodin. Acta, 17(6), 389-400.

Bakalowicz, M., 2005. Karst groundwater: a challenge for new resources, Hydrogeol. J., 13(1), 148-160.

Barbel-Perineau, A., Emblanch, C. \& Danquigny, C., 2015. Spatial and temporal hydrodynamic variations of flow in the Karst Vadose Zone (Rustrel, France) in function of depth and fracturing density, in Hydrogeological and Environmental Investigations in Karst Systems, pp. 11-18, eds Andreo, B., Carrasco, F., Durán,, J.J., Jiménez, P. \& LaMoreaux, J., Springer.

Bawden, G.W., Thatcher, W., Stein, R.S., Hudnut, K.W. \& Peltzer, G., 2001. Tectonic contraction across Los Angeles after removal of groundwater pumping effects, Nature, 412(6849), 812-815.

Bayle, B. \& Graillot, D., 1987. Société spéléologique de Fontaine-devaucluse, Compte-rendu hydrogéologique de l'opération Spéléonaute du $2 / 8 / 85$, Fontaine de Vaucluse (The Speleonaute operation at the Fontaine de Vaucluse), Karstologiya, 9, 1-6.

Blavoux, B., Mudry, J. \& Puig, J.M., 1992. The karst system of the Fontaine de Vaucluse (Southeastern France), Environ. Geol. Water Sci., 19(3), 215225.

Boudin, F., 2004. Développement et validation d'un inclinomètre longue base de subsurface à silice et mercure: Application à des mesures géophysiques de haute résolution sur le chantier pilote du Golfe de Corinthe, PhD thesis, Université Paris 7, pp 322.

Boudin, F. et al., 2008. A silica long base tiltmeter with high stability and resolution, Rev. Sci. Instrum., 79(3), 034502, doi:10.1063/1.2829989.

Braitenberg, C., 1999. The hydrologic induced strain-tilt signal: a review, Bull. d'Inf. Marées Terrestres, 131, 10 171-10 181.

Braitenberg, C., Romeo, G., Taccetti, Q. \& Nagy, I., 2006. The very-broadband long-base tiltmeters of Grotta Gigante (Trieste, Italy): secular term tilting and the great Sumatra-Andaman islands earthquake of December 26, 2004, J. Geodyn., 41(1), 164-174.

Carrière, S.D., Chalikakis, K., Sénéchal, G., Danquigny, C. \& Emblanch, C., 2013. Combining Electrical Resistivity Tomography and Ground Penetrating Radar to study geological structuring of karst Unsaturated Zone, J. Appl. Geophys., 94, 31-41.

Carrière, S.D., Chalikakis, K., Danquigny, C., Davi, H., Mazzilli, N., Ollivier, C. \& Emblanch, C., 2016. The role of porous matrix in water flow regulation within a karst unsaturated zone: an integrated hydrogeophysical approach, Hydrogeol. J., 24, 1905-1918.

Chalikakis, K., Plagnes, V., Guérin, R., Valois, R. \& Bosch, F.P., 2011. Contribution of geophysical methods to karst-system exploration: an overview, Hydrogeol. J., 19(6), 1169-1180.

Chawah, P. et al., 2015. A simple pendulum borehole tiltmeter based on a triaxial optical-fibre displacement sensor, Geophys. J. Int., 203(2), 10261038.

Cognard-Plancq, A.L., Gevaudan, C. \& Emblanch, C., 2006. Historical monthly rainfall-runoff database on Fontaine de Vaucluse karst system: review and lessons, in Karst, Cambio Climatico y Aguas Submediterraneas, pp. 465-475, eds Duran, J.J., Andreo, B. \& Carrasco, F.Y., IGME Publications.

Dal Moro, G. \& Zadro, M., 1998. Subsurface deformations induced by rainfall and atmospheric pressure: tilt/strain measurements in the NEItaly seismic area, Earth planet. Sci. Lett., 164(1), 193-203.

Devoti, R., Zuliani, D., Braitenberg, C., Fabris, P. \& Grillo, B., 2015. Hydrologically induced slope deformations detected by GPS and clinometric surveys in the Cansiglio Plateau, southern Alps, Earth planet. Sci. Lett., 419, 134-142.

Dong, D., Fang, P., Bock, Y., Cheng, M.K. \& Miyazaki, S., 2002. Anatomy of apparent seasonal variations from GPS-derived site position time series, J. geophys. Res., 107(B4), doi:10.1029/2001JB000573.

d'Oreye de Lantremange, N., 2003. Inclinomètre à niveau hydrostatiques de haute résolution en Géophysique, $P h D$ thesis, Université Catholique de Louvain, $158 \mathrm{pp}$.

Emblanch, C., Zuppi, G.M., Mudry, J., Blavoux, B. \& Batiot, C., 2003. Carbon 13 of TDIC to quantify the role of the unsaturated zone: the example of the Vaucluse karst systems (Southeastern France), J. Hydrol., 279(1), 262-274.

Evans, K. \& Wyatt, F., 1984. Water table effects on the measurement of Earth strain, Tectonophysics, 108, 323-337.

Fleury, P., Plagnes, V. \& Bakalowicz, M., 2007. Modelling of the functioning of karst aquifers with a reservoir model: application to Fontaine de Vaucluse (South of France), J. Hydrol., 345(1), 38-49.

Gaffet, S. et al., 2003. Simultaneous seismic and magnetic measurements in the Low-Noise Underground Laboratory (LSBB) of Rustrel, France, during the 2001 January 26 Indian earthquake, Geophys. J. Int., 155(3), 981-990.

Garry, B., Blondel, T., Emblanch, C., Sudre, C., Bilgot, S., Cavaillou, A., Boyer, B. \& Auguste, M., 2008. Contribution of artificial galleries to the knowledge of karstic system behaviour in addition to natural cavern data, Int. J. Speleol., 37(1), 7, doi:10.5038/1827-806X.37.1.7.

Gebauer, A., Kroner, C. \& Jahr, T., 2009. The influence of topographic and lithologic features on horizontal deformations, Geophys. J. Int., 177, 586-602.

Gilli, É., Boudin, F., Longuevergne, L., Florsch, N., Walch, J.J., Gomez, A., Depeyre, J. \& Marie, J.C., 2010. Neotectonics and current hydrologicallyinduced karst deformation. Case study of the Plateau de Calern (AlpesMaritimes, France), Geodin. Acta, 23(1-3), 49-64.

Hassani, R., Jongmans, D. \& Chéry, J., 1997. Study of plate deformation and stress in subduction processes using two-dimensional numerical models, J. geophys. Res., 102(B8), 17 951-17 965.

Hermann, T., Kroner, C. \& Jahr, T., 2013. Geoelectrical, strain and tilt investigations of hydrological processes at the broadband Geodynamical Observatory Moxa, Germany, J. Appl. Geophys., 98, 90-99.

Hisz, D.B., Murdoch, J.C. \& Germanovich, L.N., 2013. A portable borehole extensometer and tiltmeter for characterizing aquifers, Water Resour. Res., 49, 7900-7910.

Jacob, T., Chery, J., Bayer, R., Le Moigne, N., Boy, J.P., Vernant, P. \& Boudin, F., 2009. Time-lapse surface to depth gravity measurements on a karst system reveal the dominant role of the epikarst as a water storage entity, Geophys. J. Int., 177(2), 347-360.

Jacob, T., Chéry, J., Boudin, F. \& Bayer, R., 2010. Monitoring deformation from hydrologic processes in a karst aquifer using long-baseline tiltmeters, Water Resour. Res., 46(9), doi:10.1029/2009WR008082.

Jahr, T., Jentzsch, G. \& Weise, A., 2009. Natural and man-made induced hydrological signals, detected by high resolution tilt observations 
at the Geodynamic Observatory Moxa/Germany, J. Geodyn., 48(3), $126-131$.

Jeanne, P., Guglielmi, Y., Lamarche, J., Cappa, F. \& Marié, L., 2012. Architectural characteristics and petrophysical properties evolution of a strikeslip fault zone in a fractured porous carbonate reservoir, J. Struct. Geol., 44, 93-109.

Kümpel, H.J., Peters, J.A. \& Bower, D.R., 1988. Nontidal tilt and water table variations in a seismically active region in Quebec, Canada, Tectonophysics, 152, 253-265.

Lefahler, B. \& Sanna, J., 1990. Trou Souffleur (Saint Christol d'Albion, Vaucluse) : une suite vers l'aval (Souffleur shaft: a continuation at depth), Spelunca, 37, 35-40.

Léonide, P., Borgomano, J., Masse, J.P. \& Doublet, S., 2012. Relation between stratigraphic architecture and multi-scale heterogeneities in carbonate platforms: The Barremian-lower Aptian of the Monts de Vaucluse, SE France, Sediment. Geol., 265, 87-109.

Longuevergne, L., Boy, J.P., Florsch, N., Viville, D., Ferhat, G., Ulrich, P., Luck, B. \& Hinderer, J., 2009. Local and global hydrological contributions to gravity variations observed in Strasbourg, J. Geodyn., 48(3), 189-194.

Masse, J.P., 1969. Contribution a l'étude de l'Urgonien (Barrémien Bédoulien) des Monts de Vaucluse et du Luberon [Contribution to the study of the Urgonian (Barremian-Bedoulian) of the Vaucluse and the Luberon mountains], Bureau de Recherches Géologiques et Minières, $59 \mathrm{pp}$.

Maufroy, M., 2010. Caractérisation et modélisation numérique de l'effet de site topographique 3D: Application à la Grande Montagne de Rustrel, Vaucluse, $P h D$ thesis, University of Nice, $245 \mathrm{pp}$.

Meertens, C.M. \& Wahr, J.M., 1986. Topographic effect on tilt, strain, and displacement measurements, J. geophys. Res., 91(B14), $14057-14062$.

Ollivier, C., Danquigny, C., Mazzilli, N. \& Barbel-Perineau, A, 2015. Contribution of hydrogeological time series statistical analysis to the study of Karst Unsaturated Zone (Rustrel, France), in Hydrogeological and Environmental Investigations in Karst Systems, pp. 27-33, eds Andreo, B., Carrasco, F., Durán,, J.J., Jiménez, P. \& LaMoreaux, J., Springer.

Puig, J.M., 1987. Le système karstique de la Fontaine de Vaucluse. Hydrogéologie, $P h D$ thesis, Université d'Avignon, 208 pp.

Rutqvist, J., 2012. The geomechanics of CO2 storage in deep sedimentary formations, Geotech. Geol. Eng., 30(3), 525-551.

Schuite, J., Longuevergne, L., Bour, O., Boudin, F., Durand, S. \& Lavenant, N., 2015. Inferring field-scale properties of a fractured aquifer from ground surface deformation during a well test, Geophys. Res. Lett., 42(24), $10696-10703$.

Seat, H.C. et al., 2012. Dual-modulation fiber Fabry-Perot interferometer with double reflection for slowly-varying displacements, Opt. Lett., 37(14), 2886-2888.

Sénéchal, G., Rousset, D. \& Gaffet, S., 2013. Ground-penetrating radar investigation inside a karstified limestone reservoir, Near Surf. Geophys., 11(3), 283-291.

Tenze, D., Braitenberg, C. \& Nagy, I., 2012. Karst deformations due to environmental factors: evidences from the horizontal pendulums of Grotta Gigante, Italy, Boll. Geofis. Teor. Appl., 53(3), 331-345.

Van Dam, T.M. \& Wahr, J.M., 1987. Displacements of the Earth's surface due to atmospheric loading: effects on gravity and baseline measurements, J. geophys. Res., 92(B2), 1281-1286.

Vasco, D.W., Rucci, A., Ferretti, A., Novali, F., Bissell, R.C., Ringrose, P.S., Mathieson, A.S. \& Wright, I.W., 2010. Satellite-based measurements of surface deformation reveal fluid flow associated with the geological storage of carbon dioxide, Geophys. Res. Lett., 37(3), L03303, doi:10.1029/2009GL041544.

Weise, A., Jentzsch, G., Kiviniemi, A. \& Kääriäinen, J., 1999. Comparison of long-period tilt measurements: results from the two clinometric stations Metsähovi and Lohja, Finland, J. Geodyn., 27, 237-257.

Wenzel, H.G., 1994. Earth tide data processing package ETERNA 3.20, Marées terrestres, 120, 9019-9021. 